supply problems. In a written answer in the House of Commons on July 16, the Secretary of State for Industry, Trade and Regional Development, Mr. E. Heath, stated that if the preliminary assessment now being made by the North-West Study Group of the suggested Morecambe Bay and Solway barrage schemes showed that the expenditure would be justified, the examination would include a full technical and economic investigation of these projects.

\section{Large-scale Distillation and De-salting Plants}

RePLying to a question in the House of Lords on July 15, the Joint Parliamentary Secretary of State for Education and Science, the Earl of Bessborough, said that the Atomic Energy Authority's preliminary investigations of the use of nuclear reactors for providing heat for sea-water utilization plants indicated that, to be economic, the reactors would need to be very large, and this function would have to be combined with the production of electricity. In addition to producing base load electricity, such a reactor station might provide a considerable quantity of fresh water as a by-product at a price within the range of interest for domestic and industrial users in certain areas. The necessary continuous demand for electricity on a large scale limited the number of areas in which such dual-purpose reactors could be economic. Further development in the technology of de-salting plants was required and the Authority was in elose touch with the Department of Scientific and Irıdustrial Research. It was also represented on the panel of experts set up by the International A.tomic Energy Agency to investigate the possibilities of these plants in developing areas. British industry was taking a leading part in the construction of large-scale distillation plant and provided some 70 per cent of land-based plants in the world.

\section{Planning and Amenities}

The annual report of the Sheffield and Peak District Branch of the Council for the Preservation of Rural England directs attention to ways in which the importance of the preservation of amenities, in central planning, is being undermined (Pp. 26. Sheffield: Council for the Preservation of Rural England. Sheffield and Peak District Branch, 1964). Difficulties of æsthetic control were aggravated by the Central Development Order of 1950 , and in the same year the Schuster Report tended to lessen the importance of resthetics in the training of qualified officers. Another serious blow followed in 1951, when the word 'Planning' was left out of the Ministry's title and "The order and seemliness striven for so long began to disintegrate again". Now, alarmed by the unexpected rise in population, the Minister has hinted that 'Green Belts' are not inviolate, and has thus loosened the restraints on ill-sited development of rural land in a way that may be bitterly regretted by coming generations. "We are thus losing at a greater pace than ever a countryside that has been called "the loveliest in the world" ". Now, at last, influenced by experienced planners, we are beginning to recognize that regional planning is a necessity. "This has been not unfavourably received by urban authorities, so long as it is understood that their own town or city should be the central influence in the region."

\section{British Mammals}

The Identification of British Mammals, by G. B. Corbet, published by the British Museum (Natural History), is an excellent guide to the classification and identification of the sixty-odd species of mammals found in the British Isles (Pp. iii +46 . London: British Museum (Natural History), 1964. 4s.). It is intended mainly for the amateur naturalist, but will be equally useful to the professional zoologist. The principles of classification are first explained and then follows a list of the British mammal fauna, giving the synonymy and status of each species. The main part of the pamphlet consists of keys for identifying the different species by external features-field identification is not included. There is an interesting list of possible additions to the fauna, a select bibliography, and a good index.

\section{The Geological Museum, London}

THE fourth edition of $A$ Short Guide to the Exhibits of the Geological Museum in South Kensington starts with a brief history of the Museum and then gives a summary of the general arrangement of the exhibits (Pp. 36. London: H.M.S.O., 1964. 2s. 6d.). The visitor is then taken on a short tour of the galleries and is thus able to obtain a broad idea of the scope and nature of the display collections. The well-known dioramas in the Museum are illustrated, and with these and other pictures even a visitor not acquainted with geology should be able to view the exhibits intelligently. The text of this useful and handy pamphlet is clearly written, with few technical phrases.

\section{Nuclear Magnetic Resonance Current Literature Service}

A NEW literature searching service, dealing with papers on nuclear magnetic resonance, nuclear quadrupole resonance and electron paramagnetic resonance, is to be established by Butterworths, the publishers of Documentation of Molecular Spectroscopy. This will take the form of a numbered and coded literature list which is searched by means of a peep-hole index of coded punched cards. The coding has been devised to enable searches to be made from two main starting points: (1) from the general contents of the paper, the nature of the problem investigated, and details of the techniques and apparatus described; (2) from the chemical classification of the compounds examined. The literature lists will give the title, author, journal or other source of publication, date and other relevant information, including, where neeessary, a brief note on the content. It is hoped that, as they will be issued four times a year, they will offer: (a) an up-to-date and comprehensive source of rapid information which is easily retrievable by the use of the peep-hole index containing 105 cards per issue; (b) a current documentation of the entire field of magnetic resonance spectroscopy. At the end of the subscription period of two years the peep-hole index cards provided with each issue will be replaced by a consolidated peephole card index, thus making possible the searching of the literature in compact two-year batches. An alphabetical list of authors will also appear. A detailed Instruction Manual will be provided giving particulars of the coding. The service will cover the literature published since the beginning of 1963. It is also planned to produce, in due course, a collection of references covering the years 1946-62. A service similar to that described here, but covering infra-red, Raman and microwave spectroscopy, has been in operation as part of Documentation of Molecular Spectroscopy since the beginning of 1963. This is supplied to subscribers as part of their subscription but is also available separately. Full details of these services are available from Butterworths, 88 Kingsway, London, W.C.2.

\section{University News :}

London

DR. A. O. Betss, University lecturer at the School of Veterinary Medicine, Cambridge, has been appointed to the chair of veterinary microbiology and parasitology at the Royal Veterinary College. Dr. J. Edelman, reader in enzymology at the Imperial College of Science and Technology, has been appointed to the chair of botany at Queen Elizabeth College. Dr. F. G. Foster, reader in statistical computing at the London School of Economics and Political Science, has been appointed to the chair of computational methods at that School. Dr. W. W. Schwabe, a member of the staff of the Agricultural Research Council Unit of Plant Morphogenesis and 